\title{
GENERALIDADES DE LOS MECANISMOS ALTERNATIVOS DE SOLUCIÓN DE CONTROVERSIAS
}

\author{
OVERVIEW OF ALTERNATIVE DISPUTE RESOLUTION MECHANISMS
}

\author{
Verónica Castro-Jiménez ${ }^{1} *$ iD. \\ 1. Escuela Judicial del Estado de Tabasco, México. vekaoca@gmail.com \\ * Autor de correspondencia: Verónica Castro-Jiménez, correo electrónico: vekaoca@gmail.com
}

\section{RESUMEN}

El acceso a la justicia es una vía de garantía de este derecho humano a la ciudadanía mediante su administración. En el estado mexicano el artículo 17 Constitucional dispone de mecanismo heterocompositivo (juicio) y autocompositivo (negociación, mediación, conciliación, arbitraje) aplicables en diversas materias y conforme a su normativa. En ese sentido, es importante considerar la profesionalización de los facilitadores a cargo de llevar la gestión de conflictos de mecanismos que requiere considerar ser aplicados desde los principios de los mismos a partir de la justicia alternativa. Aunque hay un avance en la materia este documento expone la justicia alternativa a partir de los mecanismos alternativos en México.

Palabras clave: Derecho humano; facilitador; justicia alternativa; solución de conflictos.

Cómo citar:

Castro-Jiménez, Verónica. (2021). Generalidades de los mecanismos alternativos de solución de controversias. Revista de Investigaciones Universidad del Quindio, 33(S2), 213-218. https://doi.org/10.33975/riuq.vol33nS2.453 


\begin{abstract}
Access to justice is a way to guarantee this human right to citizenship through its administration. In the Mexican state, Article 17 of the Constitution has a heterocompositive (trial) and autocompositive (negotiation, mediation, conciliation, arbitration) mechanism applicable in various matters and in accordance with its regulations. In this sense, it is important to consider the professionalization of the facilitators in charge of managing the conflict of mechanisms that requires considering being applied from the principles of the same from the alternative justice. Although there is progress on the matter, this document exposes alternative justice based on alternative mechanisms in Mexico.
\end{abstract}

Keywords: Human right; facilitator; alternative justice; conflict resolution.

\title{
INTRODUCCIÓN
}

En México a partir de las reformas constitucionales de 2008 en materia de justicia alternativa y posteriormente en el año 2011 en materia de derechos humanos, afianza en el estado mexicano un sistema de administración de justicia que coadyuve a la dilatación de los procesos y resolución de casos ante los tribunales en México.

Es una emergencia a las condiciones subyacentes y circunstanciales de la justicia es acceso a la justicia como derecho humano que todo individuo tiene como ciudadano universal en el que el Estado procura su divulgación y aplicación a través de mecanismos autocompositivos con legitimidad jurídica estableciendo las instituciones con personal capacitado, garantizando este derecho de forma pública y privada, debido a que los juzgados o tribunales se encuentran saturados de trabajo y no dan de forma rápida y expedita la justicia que las personas requieren.

En ese sentido, la justicia alternativa conlleva un proceso en el que las partes involucradas en el conflicto dan solución al mismo. "Quienes entran en este procedimiento pasan a ser los actores principales en la resolución de sus diferencias, e implícitamente se refiere a la oportunidad de llegar a un acuerdo por las personas involucradas en un conflicto, participando de manera colaborativa con relación a alguna afectación en sus bienes o sus derechos, y donde el fin principal es que las partes alcancen una solución que satisfaga sus intereses recíprocos.” (Cabrera \& Aguilar, 2019).

Con ello, se lleva un proceso que tiene impacto más allá del sistema de justicia, debido a que las personas ante situaciones de conflicto que no ameritan un proceso jurisdiccional como tal, desde la voluntariedad y asistidas por un facilitador llegan a la solución del mismo. Se aplica un proceso que aboga por solucionar conflictos desde el diálogo y la comunicación encontrándonos como sociedad en un proceso de transición y fortalecimiento para una cultura de paz y concordia.

\section{METODOLOGÍA}

Para el desarrollo de este documento Generalidades de los Mecanismos Alternativos de Solución de Controversias se empleó un enfoque cualitativo con alcance documental, descriptivo e interpretativo. La justicia alternativa basado en un esquema de construcción jurídica con alcance social debe conocer e identificar la naturaleza del conflicto desde sus entrañas es pertinente citar a Luhmann (2006) quien 
señala que no puede observarse a la sociedad desde fuera, pues lleva a cabo su actividad en la sociedad misma, y es precisamente esto lo que tendría que saberse.

\section{RESULTADO}

La justicia alternativa es el sistema de justicia que ha venido evolucionando en las últimas décadas, la solución de conflictos a través de metodologías diferentes a los procesos o procedimientos previstos en la justicia tradicional derivado de ello, los medios alternativos de resolución de conflictos, tienen la finalidad que el sistema de justicia tradicional, que es el acceso de las personas a la justicia.

A nivel internacional el acceso a la justicia está reconocido en el artículo 8 "Garantías Judiciales" de la Convención Americana sobre Derechos Humanos en el cual se establecen todos aquellos principios y criterios que lo hacen legítimo, parte del derecho de toda persona a ser oída con las garantías y en un plazo razonable por la instancia competente; a la igualdad con garantías mínimas; a ser asistido sin costo en caso de requerir de un traductor o intérprete; de ser asistido o defenderse personalmente, entre otros.

De igual forma el artículo 8.15 establece derechos similares como el de ser escuchada, tiempo, juez o autoridad competente; el artículo 25 de la Convención señala la eficacia mediante la rapidez que debe prevalecer en el acceso a la justicia, misma que no puede violar derechos fundamentales ni ser pretensiosas a denegar o limitar ese derecho.

El sistema alternativo se trata de instrumentos distintos a la tutela jurisdiccional en sentido estricto, si bien en algunos casos nacen con ocasión del acceso del conflicto a los tribunales, ya sea para prevenirlos o ya sea para intentar remediarlos en el seno mismo del proceso (Sospreda, 2014). Los procedimientos extrajudiciales de resolución de controversias en los cuales participa un tercero que no tiene la calidad de juez, sino que se ocupa de dirigir y facilita la comunicación y diálogo en el procedimiento, como ocurre en los métodos de conciliación, mediación, y en el arbitraje el árbitro o tribunal arbitral si tiene esa facultad de heterocomposición.

En el caso de México lo podemos ubicar en el artículo 17 de la Constitución Política de los Estados Unidos Mexicanos. Este artículo fundamenta el acceso a la impartición de justicia consagrada para los ciudadanos basada en los principios de justicia pronta, completa, imparcial y gratuita.

Foddai (2010) dice que la expresión de alternativa es una expresión ampliamente difundida y empleada en ámbito internacional, desde Estados Unidos hasta Europa, desde Australia hasta Asia, designa un sistema de gestión de las controversias que se sirven de métodos informales y extraprocesales.

\section{MECANISMOS ALTERNATIVOS}

- Negociación. Se establece entre las partes de forma voluntaria cuyo objetivo es llegar a un acuerdo aceptable para todos, para que este exista deben de integrarse las siguientes condiciones: mínimo de intereses comunes o complementarias; motivación por ambas partes de encontrar un acuerdo y existencia de una autonomía reconocida de forma recíproca (Martínez, 2012). En la negociación versan intereses de forma gradual y diversos, se pueden identificar algunos como: los intereses de cada una de las partes, los conflictivos que son identificados de forma negativa, los indiferentes en los que las partes saben que quieren cosas distintas, pero no llega a perjudicar sus intereses, los 
complementarios en lo que las partes saben que quieren lo mismo pero para distintos intereses y finalmente los comunes en donde las partes saben que quieren lo mismo por las mismas razones (Puchol, 2005).
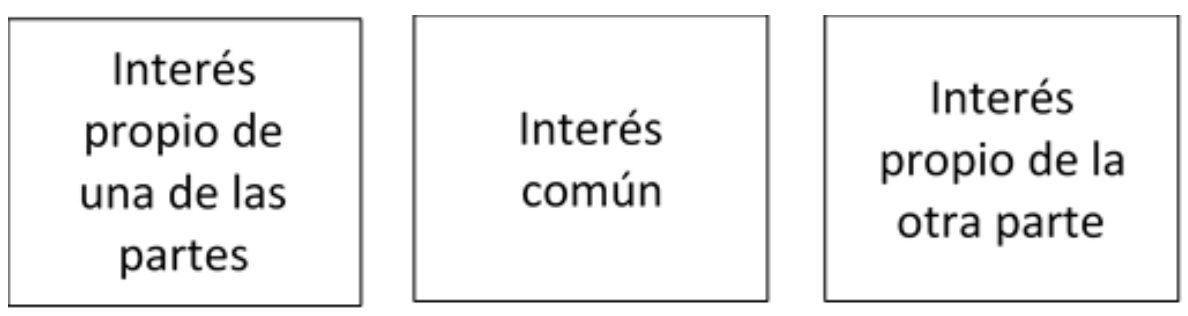

- Mediación. Baruch y Bush (2006) señalan que la premisa de ver el conflicto como oportunidades de crecimiento y transformación moral, permite una ocasión de crecimiento en dos dimensiones críticas e interrelacionadas de la moral humana, para lo cual se puede conseguir a través de la mediación transformadora en el que se revaloriza y reconoce a la otra persona; se alcanza el éxito cuando las partes como personas cambian para mejorar, en cierto grado, gracias a lo que ha sucedido en el proceso de mediación, se trabaja en dos dimensiones la primera mediante la capacidad para fortalecer el yo y la segunda mediante la capacidad de relacionarse con otros. El mediador es un profesional que lleva a efecto el procedimiento de la mediación, es un especialista y con habilidades para desarrollar las técnicas y herramientas de la mediación en el proceso, existe también la figura del comediador quien puede apoyar en el proceso para optimizarlo. "Tanto el mediador como el conciliador desempeñan un papel fundamental en la solución consensuada entre las partes en conflicto; deben ser neutrales e imparciales, con alto sentido de vida, espíritu altruista y que reconozcan la importancia del "otro" como ser humano" (Arboleda, 2017).

Esquema de elementos de mediación.

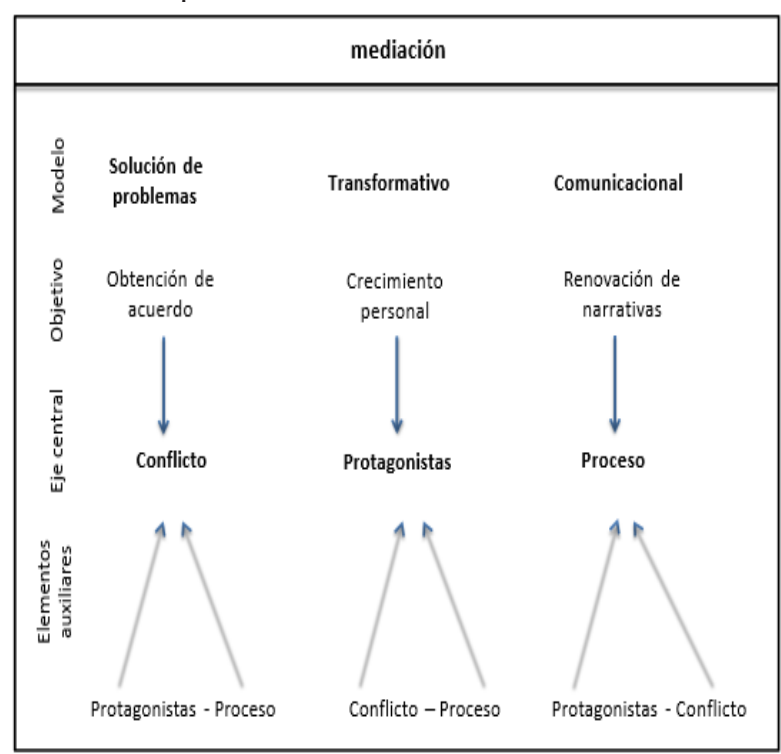

Fuente: Boqué Torremorell, Maria Carmen. (2003). Cultura de mediación y cambio social. España: Gedisa.

- Conciliación. Es un procedimiento en el que están inmersas las partes involucradas guiadas por un especialista que propone soluciones con el objeto de ir facilitando el diálogo y la búsqueda de acuerdos (LJAET, Artículo 3). Los principios36 que se pueden considerar que rigen la conciliación son: la voluntariedad por el hecho de que las partes asisten sin coacción alguna; confidencialidad 
en sentido de que todo lo que se exponga en el procedimiento no será utilizado para otros fines; la flexibilidad referente a satisfacer plenamente las necesidades de cada una de las partes; neutralidad e imparcialidad no se favorece a ninguna de las partes todo es llevado con total igualdad (Yuquilema \& Criollo, 2016). La conciliación debe entenderse desde dos aristas sustancial y procesal, debido a que a manera de que se tenga como acceso a la justicia pronta y expedita materializa una solución que abona a las garantías que otorga el Estado. El conciliador es quien facilita la comunicación entre las partes. Este profesional puede proponer, recomendar o sugerir puntos o acuerdos que las partes puedan considerar para el convenio y así poner fin de forma parcial o total a la controversia.

- Arbitraje. Es como un proceso porque como en este se dirime jurídicamente una controversia, pero no es un proceso judicial (Castillo \& Vázquez, 2006). Método de solución de conflicto en donde las partes se aseguran una solución, que no será logrado por ellas mismas, sino por un tercero profesional denominado "árbitro" dicha decisión a la solución se denomina laudo, el cual tiene carácter de obligatorio para las partes y excluye el concomiendo del conflicto a la jurisdicción (Blanco, 2013). El árbitro es una persona privada, no un juez, tiene como función escuchar lo que cada parte desee exponer para defender su punto de vista y, con base en ello, tomar una decisión vinculante dará resolución al conflicto debe ser idóneo, imparcial y neutral frente a las partes otorgando seguridad jurídica a las partes.

De los mecanismos antes descritos señala Nava y Breceda (2017) distinguen que:

"los medios alternativos de solución de conflictos constituyen mecanismos convencionales, expeditos y económicos de solución de controversias; incluyen: i) los sistemas de negociación que buscan crear un ambiente que permitan a las partes alcanzar una solución razonable por sí mismos; ii) se extienden a los sistemas que cuentan con la intervención de un tercero ajeno a la disputa, que auxiliando (mediación) o proponiendo ( conciliación) coopera para que éstas lleguen a un acuerdo por ellas mismas, y iii) alcanza a las modalidades adversariales a través de las cuales el tercero decide o resuelve (arbitraje).” (p. 209)

No sólo coadyuva al sistema de justicia en México sino es de competencia en otros ámbitos en los que fortalece una sociedad democrática y participativa.

\section{DISCUSIÓN}

La justicia alternativa es un abanico de oportunidades y posibilidades de promoción a través de la educación, en el que se difunde y fortalece la paz y concordia, el manejo y solución de los conflictos (Silva, 2020) contribuyendo a una convivencia inclusiva, participativa, justa y democrática.

En México constitucionalmente están denominados como Mecanismos Alternativos de Solución de Controversias (CPEUM, Artículo 17) son métodos autocompositivos en el que la justicia es vista de forma horizontal e inclusiva debido a que el grado de participación de las partes en el conflicto es total; hoy día se discute que el término de "alternativos" no debe ser empleados para referirse así a los métodos ya que es un sistema de justicia legal y jurídicamente reconocido, de igual forma están impactando en escenarios de conflictos ambientales, comunitarios, indígenas, vecinal, educativo, entre otros.

Para que estos mecanismos puedan funcionar en conjunto con los facilitadores es importante tener 
presentes algunos de los principios que rigen la justicia alternativa como lo son la voluntariedad basada en la autodeterminación de las partes para solicitar y asistir al procedimiento; la confidencialidad basada en que la información que se emite en el procedimiento no será divulgada por ninguna de las partes involucradas, así como el tercero profesional que lleve el procedimiento a menos que se percate que el conflicto deriva de un acto o hecho tipificado. La buena fe de las partes y el tercero en el hecho de que actúen de forma responsable e integra sin mala voluntad o ventaja; neutralidad e imparcialidad el tercero no mostrará preferencia por alguna de las partes sin favoritismo; honestidad es la forma en como el tercero profesional se maneja en los procedimiento visualizando de forma ética sus alcances y límites en el proceso; flexibilidad referida a la participación activa de las partes para la toma de decisión de su propio conflicto llevado solo por el tercero profesional quien les facilita la comunicación

\section{REFERENCIAS}

1. Arboleda López, Adriana Patricia. (2017). Conciliación, mediación y emociones: Una mirada para la solución de los conflictos de familia Civilizar. Ciencias Sociales y Humanas, 17 (33), 81-96.

2. Baruch Bush, R.A. y Folger, J.P. (2006). La promesa de la mediación, como afrontar el conflicto a través del fortalecimiento propio y el reconocimiento de los otros. Buenos Aires: Granica.

3. Boqué Torremorell, Maria Carmen. (2003). Cultura de mediación y cambio social. España: Gedisa.

4. Blanco Carrasco, Marta. (2013). Mediación y sistemas alternativos de resolución de conflictos. España: REUS.

5. Castillo Freyre, Mario, \& Vásquez Kunze, Ricardo (2006). Arbitraje: naturaleza y definición. Derecho PUCP, (59),273-284.

6. Diario Oficial de la Federación. (1917). Constitución Política de los Estados Unidos Mexicanos.

7. Foddai, María Antonietta. (2010). Mediación, arbitraje y resolución extrajudicial de conflictos en el siglo XXI. España: REUS.

8. Periódico Oficial. (2012). Ley de Acceso a la Justicia Alternativa para el estado de Tabasco.

9. Luhmann, Niklas. (2006). Sociología del riesgo. México: Universidad Iberoamericana.

10. Martínez Guillén, María del Carmen. (2012). La negociación. España: Díaz de Santos.

11. Nava GonzáLez, Wendolyne, \& Breceda Pérez, Jorge Antonio (2017). Mecanismos alternativos de resolución de conflictos: un acceso a la justicia consagrado como derecho humano en la constitución mexicana. Cuestiones Constitucionales, (37),203-228

12. Puchol, Luis. (2005). El libro de la negociación. España: Díaz de Santos.

13. Silva-Hernández, Francisca. (2020). Hacia una comprensión del conflicto en justicia alternativa. Revista de Investigaciones Universidad del Quindío, 32(1), 61-65. https://doi.org/10.33975/riuq. vol32n1.435

14. Sospedra Navas, Francisco José. (2014). Mediación y arbitraje. Los sistemas alternativos de resolución de conflictos. España: THOMSON REUTERS PROVIEW.

15. Yuquilema Gavilanes, Juan Ignacio \& Criollo Mayorga, Giovani. (2016). Teoría y práctica de la mediación y conciliación. Ecuador: CEP. 